\title{
Impact of Patient Access to Online VA Notes on Healthcare Utilization and Clinician Documentation: a Retrospective Cohort Study
}

\author{
Amanda C. Blok ${ }^{1,2}$ (1), Daniel J. Amante ${ }^{3}$, Timothy P. Hogan 4,5, Rajani S. Sadasivam³, \\ Stephanie L. Shimada ${ }^{3,4,6}$, Susan Woods ${ }^{7}$, Kim M. Nazi $^{8}$, and Thomas K. Houston ${ }^{9}$
}

'Veterans Affairs Center for Clinical Management Research, Veterans Affairs Ann Arbor Healthcare System, United States Department of Veterans Affairs, 2215 Fuller Road, Mail Stop 152, Ann Arbor, MI, USA; ${ }^{2}$ Systems, Populations and Leadership Department, School of Nursing, University of Michigan, Ann Arbor, MI, USA; ${ }^{3}$ Division of Health Informatics and Implementation Science, Department of Population and Quantitative Health Sciences, University of Massachusetts Medical School, Worcester, MA, USA; “ Veterans Affairs Center for Healthcare Organization and Implementation Research, Veterans Affairs Bedford Medical Center, United States Department of Veterans Affairs, Bedford, MA, USA; ${ }^{5}$ Department of Population and Data Sciences, UT Southwestern Medical Center, Dallas, TX, USA; ${ }^{6}$ Department of Health Law, Policy, and Management, Boston University School of Public Health, Boston, MA, USA; ${ }^{7}$ Maine Behavioral Healthcare, South Portland, ME, USA; ${ }^{8} \mathrm{KMN}$ Consulting Services, Coxsackie, NY, USA; ${ }^{2}$ Learning Health Systems, Department of Medicine, Wake Forest University, Winston-Salem, NC, USA.

BACKGROUND: In an effort to foster patient engagement, some healthcare systems provide their patients with open notes, enabling them to access their clinical notes online. In January 2013, the Veterans Health Administration (VA) implemented online access to clinical notes ("VA Notes") through the Blue Button feature of its patient portal.

OBJECTIVE: To measure the association of online patient access to clinical notes with changes in healthcare utilization and clinician documentation behaviors.

DESIGN: A retrospective cohort study.

PATIENTS: Patients accessing My HealtheVet (MHV), the VA's online patient portal, between July 2011 and January 2015.

MAIN MEASURES: Use of healthcare services (primary care clinic visits and online electronic secure messaging), and characteristics of physician clinical documentation (readability of notes).

KEY RESULTS: Among 882,575 unique portal users, those who accessed clinical notes $(16.2 \% ; N=122,972)$ were younger, more racially homogenous (white), and less likely to be financially vulnerable. Compared with non-users, Notes users more frequently used the secure messaging feature on the portal (mean of 2.6 messages (SD 7.0) v. 0.87 messages (SD 3.3) in January-July 2013), but their higher use of secure messaging began prior to VA Notes implementation, and thus was not temporally related to the implementation. When comparing clinic visit rates pre- and post-implementation, Notes users had a small but significant increase in rate of 0.36 primary care clinic visits (2012 v. 2013) compared to portal users who did not view their Notes $(p=0.01)$. At baseline, the mean reading ease of primary care clinical notes was 53.8 (SD 10.1) and did not improve after implementation of VA Notes.

CONCLUSIONS: VA Notes users were different than patients with portal access who did not view their notes online, and they had higher rates of healthcare service use prior to and after VA Notes implementation. Opportunities

There were no prior presentations of this work.

Received December 23, 2019

Accepted October 7, 2020

Published online January 14, 2021 exist to improve clinical note access and readability.

J Gen Intern Med 36(3):592-9

DOI: $10.1007 / \mathrm{s} 11606-020-06304-0$

(c) Society of General Internal Medicine (This is a U.S. government work and not under copyright protection in the U.S.; foreign copyright protection may apply) 2021

\section{BACKGROUND}

Effectively managing chronic diseases requires both high-quality healthcare and ongoing patient engagement. ${ }^{1,2}$ Patients living with chronic diseases need support for a range of selfmanagement tasks, including accessible, understandable information about their condition and treatment. ${ }^{3}$ Since meaningful use requirements have incentivized the use of health information technology, electronic health records (EHRs) with tethered patient portals have increased. ${ }^{4,5}$ Such portals provide patients with access to their personal health information. Portal features vary, and can include logging and tracking of health information, transactions with the health system such as refilling prescriptions or scheduling appointments, and communicating with healthcare teams through asynchronous, secure messaging. ${ }^{6}$ Some patient portals provide patients with access to additional information from the EHR, such as the clinical notes authored by providers. ${ }^{7,8}$

In 2000, the Veterans Health Administration (VA) became the first healthcare system to pilot test patient access to all clinical notes authored by providers through their online patient portal. ${ }^{9,10}$ Outside of VA, similar trends have evolved. OpenNotes, an initiative to offer patients access to their clinical notes online, was first implemented in 2010 as an exploratory study at three medical centers. ${ }^{1-13}$ It has since expanded to include other healthcare institutions, an estimated 40 million patients now having online access to their clinical notes. ${ }^{14}$ In January 2013, the VA implemented full national deployment of open clinical notes, which we hereon refer to as "VA Notes", with patients. VA Notes include progress and consult 
notes from primary care, specialty care, mental health, social work, nursing, and patient-clinical-team secure messaging exchanges that have been saved as notes. ${ }^{15,16}$ Patients with a premium authenticated account (which affords access to all portal features following an identity verification process) through the VA's patient portal, My HealtheVet, have the ability to view and download their notes. As of May 2020, there are 5.4 million registered users, 3.3 million of whom have premium accounts with access to VA Notes.

Veterans represent a unique patient population ${ }^{17}$ with high medical complexity ${ }^{18}$ including multiple chronic diseases ${ }^{19,20}$ and mental health disorders. ${ }^{21}$ Clinical notes have the potential to assist veterans in chronic disease management in various ways, including making the details of previous visits readily accessible and informing preparations for future visits. A survey of experiences among Veterans who were early adopters of reading their clinical notes ${ }^{15}$ revealed that the notes helped them understand $(91.8 \%)$ and manage aspects of their chronic diseases, such as taking medications as prescribed (80.1\%), being prepared for clinic visits $(88.6 \%)$, and remembering their care plan $(91.9 \%){ }^{22}$ While some early adopters reported reaching out to contact their provider or healthcare team after reading the notes $(11.9 \%)$, the impact of viewing clinical notes on subsequent healthcare utilization remains unknown.

Following on this earlier survey ${ }^{15}$ this analysis focuses on access to notes in a national cohort of VA patients. This analysis leverages the availability of data from the Veterans Health Administration (VHA), the largest integrated healthcare system in the USA, providing care at 170 medical centers and 1074 outpatient sites of care, and serving nine million veterans each year. ${ }^{23} \mathrm{We}$ addressed three research questions. First, who uses notes? We hypothesized (H1a) that consistent with recent literature on OpenNotes, a digital divide may exist, with older and lower income patients less likely to access their notes, ${ }^{24-26}$ as well as racial minority patients and patients with less than high school education as less likely to access their notes. $^{26,27}$ Additionally, we hypothesized (H1b) those with chronic disease would be more likely to access notes due to their greater clinical need and more frequent interactions with the healthcare system. Second, are notes users more likely to subsequently contact their clinical team (online and in-person) than non-users? We hypothesized (H2a) that accessing clinical notes would stimulate patient questions or sharing of new health information, thus increasing online patient portal secure messaging compared to non-users. Additionally, we hypothesized $(\mathrm{H} 2 \mathrm{~b})$ that notes users would have a higher rate of primary care service utilization than non-users. The impact of access to notes on utilization is largely unknown, ${ }^{28}$ with some reports of increased use of healthcare services related to access. ${ }^{29,30}$ Third, was there a difference in how clinicians wrote their notes, compared with notes written pre-notes? We hypothesized (H3) an increase in clinical note readability postnotes given provider knowledge of their patients having access to their clinical notes.

\section{METHODS}

\section{Study Design}

We conducted a retrospective, longitudinal cohort study of $4,235,380$ patients who received VA care (had at least one visit annually) between January 2011 and January 2015. This time window was selected to best examine the immediate impact of VA Notes implementation, early-on after becoming nationally available. Among this cohort, we examined patients who used the portal $(N=882,575)$, comparing patients who accessed notes through the portal (notes users) and those who did not (non-users).

We examined the impact of VA Notes on communication with providers via secure messaging and primary care utilization, comparing differences between notes users and non-users before and after January 2013. We further explored the readability of clinical notes before and after January 2013. This study was reviewed and approved by the Edith Nourse Rogers Memorial Veterans Hospital and the University of Massachusetts Medical School Institutional Review Boards.

\section{Data Sources and Measures}

Data for the variables of interest (demographic characteristics, use of the portal, use of healthcare services, text of clinical notes, frequency of viewing notes and secure messages, number of primary care visits) were extracted from the VA corporate data warehouse for the time period from January 2011 to January 2015. As noted above, notes first became available to all patients in January 2013, and data on patient viewing of notes became available in July 2013. The "Pre-notes" (i.e., before implementation) time period was defined as July 2011January 2013 and the "Post-notes" (i.e., after implementation) time period was defined as July 2013-January 2015.

\section{Analytic Plan}

To address the first research question, we examined demographic and clinical characteristics of all VA patients and compared them with patients with portal accounts who did and did not access notes. Accessing notes was defined as a patient viewing or downloading their clinical notes online using the portal between July 2013 and January 2015. Demographic characteristics included age, gender, race, a marker of financial vulnerability (defined as eligibility for free care based on an annual VA financial assessment), marital status, distance from the nearest facility, residing in an urban or rural setting, and smoking status. Clinical characteristics included indicators for high priority chronic diseases in VA. We examined differences in characteristics between notes users and nonusers using chi-square tests.

The second research question explored the relationship between patients accessing notes, and utilization of secure messaging and clinical services. Utilization was measured by the counts of secure messages and the number of primary care visits in time periods of 6 months and 1 year, respectively, 
between June 2011 and January 2015. We report the mean and median of these counts in 6-month intervals between these dates, with the difference between notes users and non-users for each time period. We conducted interrupted time series analyses, implemented using a segmented regression method, comparing the change in utilization of secure messaging and primary care provider appointments among those who did or did not access notes. The model was implemented using a generalized estimating equation appropriate for repeated measures (annual rates per year) within individuals, and using an auto-regressive correlation structure. Variables were included in the model to represent group (notes users and nonusers), study time, pre-post implementation, and interaction terms to test change in slope within groups, as well as the difference of differences in slopes (group by time). We chose not to adjust for number of chronic conditions because we conceptualized them as part of the causal pathway driving the association between access to notes and increased utilization of services. In this large sample, we recognize that even small differences in slope of change may be significant. Thus, in addition to reporting statistical significance, we identified prior work that demonstrated a change in visits, and use a change of 0.7 clinic visits per year as a meaningful cutoff. ${ }^{30}$

The final research question examined the readability of notes before and after they became available to patients. To accomplish this, a purposeful sample of VA primary care providers (PCPs) with the highest rates of patients accessing their notes under their care was identified (top $1 \%$ nationally). Our rationale for targeting this sample was that clinicians with a higher proportion of patients who accessed their notes may be more likely to alter their documentation behaviors. Among the 40 PCPs who had the highest percentage of portal users in their panel, we randomly selected 100 patients who had accessed notes. From each of these patients, we pulled 3 notes pre-implementation and 3 notes post-implementation, and examined them for readability. Readability was assessed using universally accepted scales for evaluating readability of medical information: ${ }^{31}$ the Flesch reading ease scores (FRES) and the Flesch-Kincaid grade level (FKGL). ${ }^{32,33}$ The FRES quantifies how easy text is to read on a scale from 0 to 100 with a higher score indicating easier to read text and the FKGL estimates the grade level of text by assessing word count, words per sentence, and average number of syllables per word. The number and frequency of abbreviations were also assessed. These metrics were assessed for the entire note, and its subcomponents, including the history of present illness, the assessment, and the plan. These subcomponents were selected based on relevance to chronic disease management and because they are least likely to be influenced by copy-andpaste templates, unlike physical exam notes. Readability metrics were calculated using Microsoft Office Word 2016 builtin calculator. Changes in readability statistics from pre- to post-VA Notes implementation were determined using paired $t$ tests. Analyses were performed in STATA software version 13.1 (StataCorp, College Station, TX).

\section{RESULTS}

Among patients in our longitudinal cohort $(N=4,235,380)$, $N=882,575$ (21\%) had accessed the portal in 2013. Among these patient portal users, $14 \%(N=122,972)$ were notes users and had accessed their VA Notes online at least once in 2013.

\section{Research Question 1: Who Uses VA Notes?}

The 122,972 notes users were more likely to be white $(80.2 \%$ v. $75.1 \%$ ) and less likely to qualify for free care based on income (16.5\% v. $19.2 \%)$ than non-users(Table 1). Additionally, notes users were more likely to be women $(11.5 \% \mathrm{v}$. $10.2 \%)$ and married $(64.6 \%$ v. $60.6 \%)$. As hypothesized (H1b), notes users were more likely to have a chronic condition than those who did not access them.

\section{Research Question 2: Was VA Notes Use Associated with Change in Online Electronic Secure Messaging and In-person Healthcare Utilization?}

Patients who accessed their notes between July 2013 and January 2015 were already using secure messaging more frequently at the time of VA Notes implementation in January 2013 (mean 2.6 v. 0.9 messages among non-users) (Fig. 1). Between-group differences in rates of secure messaging had begun to widen over time prior to the implementation, and this trend continued after January 2013. Consistent with the visual in Figure 1, we found a small, yet significant, increase in slope pre-notes versus post-notes (the small coefficient from the interrupted time series favored non-users; difference of differences, $p=0.000$ ).

Notes users had more primary care clinical appointments per year pre-notes compared with those who did not access their notes, and their visits increased over time (from 3.09 visits in 2012 to 3.77 visits in 2013) (Fig. 2). The increase in clinic visits was greater than for non-users, revealing a difference in increase of 0.36 clinical visits (users $=.29$ visits, nonusers: -.07 visits) between the two groups directly before (in 2012) and after (2013) implementation. We noted a significant, yet minimal, difference in the slope of increase in clinic appointments between those who accessed and those who did not access their notes pre-and post-implementation (difference of differences, $p=0.01$ ).

\section{Research Question 3: Did Clinical Documentation Change After VA Notes Implementation?}

The average clinical note was written with a reading ease of 53.8 (SD 10.1) (on a scale of 1 to 100, with a higher number indicating greater ease) pre-notes and readability did not improve post-notes(Table 2). In fact, some measures suggested an increase in complexity post-notes, with an increase in words per sentence (mean difference 1.0; SD $1.5 ; p<0.001$ ) and grade level (mean difference 0.7 ; SD $1.3 ; p<0.01$ ), and a 
Table 1 Demographic and Health Characteristics of All Patients Accessing VA Care, Portal Users Who Accessed VA Notes, and Those Who Did Not Access Notes

\begin{tabular}{|c|c|c|c|}
\hline \multirow[t]{2}{*}{ Demographic characteristics } & \multirow[t]{2}{*}{ All Veterans $*, N=4,235,380$} & \multicolumn{2}{|c|}{ Portal users $^{\dagger}, N=882,575$} \\
\hline & & $\begin{array}{l}\text { Did not access Notes, } \\
N=759,603\end{array}$ & $\begin{array}{l}\text { Accessed Notes", } \\
N=122,972\end{array}$ \\
\hline Average age, $m$ (SD) & $63.4(15.1)$ & $58.3(14.7)$ & $57.9(12.4)$ \\
\hline \multicolumn{4}{|l|}{ Gender $(\%)$} \\
\hline Female & 5.1 & 10.2 & 11.5 \\
\hline Male & 95.0 & 89.8 & 88.5 \\
\hline \multicolumn{4}{|l|}{ Race $(\%)$} \\
\hline White & 71.3 & 75.1 & 80.2 \\
\hline African American & 14.7 & 11.8 & 9.1 \\
\hline Unknown & 11.1 & 10.0 & 8.0 \\
\hline Other & 2.9 & 3.1 & 2.7 \\
\hline Marker of economic need ${ }^{\S}$ & 25.5 & 19.2 & 16.5 \\
\hline \multicolumn{4}{|l|}{ Marital status $(\%)$} \\
\hline Married & 57.3 & 60.6 & 64.6 \\
\hline Divorced & 21.9 & 21.1 & 20.4 \\
\hline Never married & 10.9 & 11.2 & 9.5 \\
\hline Separated/single & 3.0 & 2.7 & 2.3 \\
\hline Unknown & 6.9 & 4.4 & 3.2 \\
\hline Miles from nearest facility, $m$ (SD) & $45.4(86.0)$ & $44.7(93.1)$ & $43.7(84.5)$ \\
\hline \multicolumn{4}{|l|}{ Environment $(\%)$} \\
\hline Isolated & 6.6 & 5.0 & 5.3 \\
\hline Small rural & 7.5 & 6.0 & 6.4 \\
\hline Large rural & 13.7 & 12.1 & 12.6 \\
\hline Urban & 72.3 & 76.8 & 75.6 \\
\hline \multicolumn{4}{|l|}{ Smoking status (\%) } \\
\hline Current & 22.5 & 20.6 & 20.5 \\
\hline Former & 26.9 & 26.2 & 27.1 \\
\hline Never & 29.5 & 31.8 & 30.9 \\
\hline Unknown & 21.1 & 21.4 & 21.5 \\
\hline \multicolumn{4}{|l|}{ Clinical characteristics $(\%)^{\prime}$} \\
\hline Hyperlipidemia & 63.3 & 59.3 & 62.7 \\
\hline Hypertension & 63.1 & 62.4 & 67.1 \\
\hline Diabetes & 27.6 & 28.0 & 29.6 \\
\hline Depression & 26.9 & 33.9 & 40.9 \\
\hline Coronary artery disease & 22.6 & 18.5 & 19.3 \\
\hline Post-traumatic stress disorder & 14.6 & 19.4 & 19.8 \\
\hline Chronic obstructive pulmonary disease & 14.2 & 12.6 & 14.2 \\
\hline Stroke & 3.5 & 2.9 & 2.8 \\
\hline Traumatic brain injury & 1.4 & 2.2 & 2.4 \\
\hline Spinal cord injury & 0.3 & 0.6 & 0.6 \\
\hline
\end{tabular}

*Between June 2011 and January 2015. †Premium authenticated account. $t$ Patients who accessed clinical notes in their electronic health record, including notes from physicians, nurses, and other healthcare personnel, following the VA Notes implementation. \$Means test: a marker of economic need defined as eligibility for free care based on an annual VA financial assessment. These are the percent of Veterans below the "means test" financial threshold. ${ }^{\prime}$ Total $N$ for clinical characteristics varies slightly $(<1.5 \%)$ due to missing administrative data. Differences between portal users who did access clinical notes and those who did not access clinical notes were all significant. Calculated $p$ values for the majority of differences were a $p$ of $<$ 0.001 , with the exceptions of Veterans with stroke $(p=0.005)$ and spinal cord injury $(p=0.002)$

decrease in reading ease (mean difference $-3.1 ; \mathrm{SD} 9.0 ; p=$ 0.04 ) for the entire note. In the history of present illness portion of the note, however, there was a decrease in words per sentence (mean difference $-2.0 ; \mathrm{SD} 6.9 ; p=0.08$ ) and grade level (mean difference -1.3 ; SD $4.0 ; p=0.05$ ), while the readability in the assessment and plan was unchanged. The number and frequency of abbreviations used were unchanged pre- and post-notes.

\section{DISCUSSION}

We found those who accessed their notes differed sociodemographically from those who did not. While recent OpenNotes literature suggests racial minority and less educated patients are more likely to value and benefit from access to clinical notes online, ${ }^{26,27}$ white patients are more likely to access portals ${ }^{24,34,35}$ and to view their notes online. ${ }^{25}$ Older patients, men, and those socioeconomically disadvantaged are less likely to use portals. $^{35,34}$ Although the digital divide has narrowed in recent years for the elderly and lower income patients, who are among the fastest growing subset of Internet users, ${ }^{36,37}$ our work has further confirmed a digital divide even among portal-using patients.

Consistent with the literature, ${ }^{34}$ we found that patients with chronic conditions were more likely to access their notes. Of those who have used OpenNotes, patients with fair or poor health more often describe experiencing higher levels of coordination of care and self-care than those with excellent health. ${ }^{38}$ Due to veterans' complex healthcare 


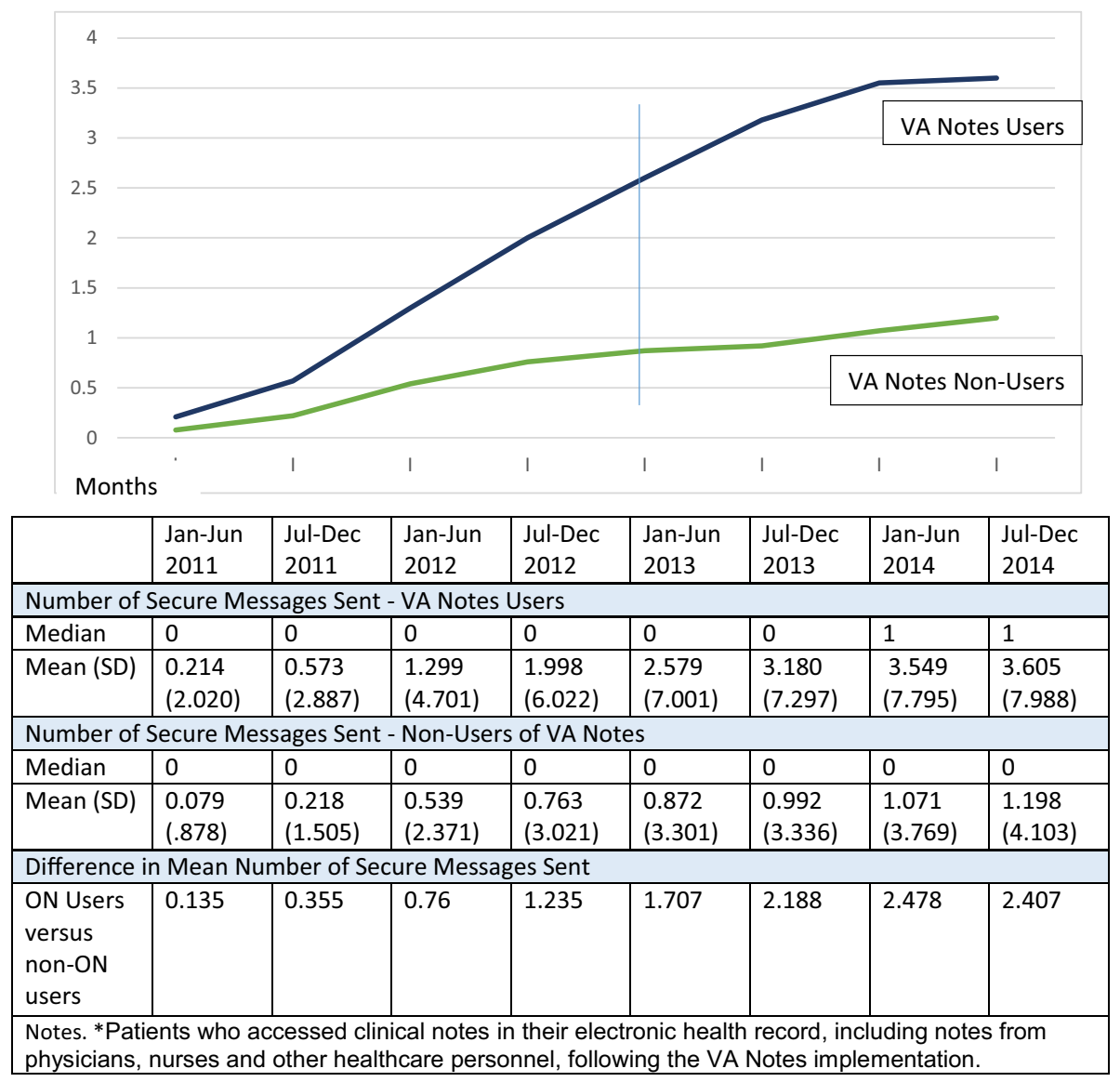

Figure 1 Average number of secure messages sent: VA Notes users versus non-users pre- and post-VA Notes implementation. VA Notes users are patients who accessed clinical notes in their electronic health record, including notes from physicians, nurses, and other healthcare personnel, following the VA Notes implementation.

needs, leveraging notes for increased efficiency and effectiveness of care coordination through sharing downloaded notes with family or caregivers and non-VA healthcare providers is possible. Due to high interest from portal users, ${ }^{39}$ VA is currently piloting a delegation feature for patients to authorize others to access their information within the portal.

Reviewing clinical notes may stimulate patient information seeking or engagement. We noted a difference in increase of 0.36 clinical visits between notes users and non-users (an increase of 0.29 clinical visits for users alone). Relative to other reports, this is a small change, as Kaiser Permanente patient users of "My Health Manager" increased 0.7 visits per year after implementation. ${ }^{30}$ Note that patients who viewed notes had a greater disease burden, compared to those who did not view notes. It may be that already high utilization (due to a higher number of chronic conditions) may have prompted notes access and thus resulted in even greater service utilization. In addition, reading the notes may have prompted increased adherence to or scheduling of new appointments. Furthermore, it is important to note the overall high disease burden in our Veteran cohort. The high chronic disease burden Veterans experience may have limited their ability to increase their utilization to the same degree the general population, or that the frequency of utilization was closer to optimal for their condition severity-more so than the general population. More detailed mixed-methods analyses are needed to understand reasons for this change in slope early after VA Notes launch. Additionally, notes users were more likely to secure message providers than non-users. This may be, in part, because patients who accessed their notes were already high users of secure messaging pre-notes implementation. Access to notes may be another marker of willingness to adopt new technology.

Finally, there is no evidence clinicians are altering their note-writing behavior to improve the overall readability of their notes. This is a novel contribution to the literature. In the original OpenNotes quasi-experimental study of 105 PCPs who self-reported documentation changes after 1 year, $3 \%$ to $36 \%$ of doctors reported changing documentation content. ${ }^{13}$ Our readability metrics did not detect any substantial objective change, yet subtle changes may not have been picked up with our methods. To improve the level of reading ease, ${ }^{33,40}$ solutions such as a web-based course for VA clinicians ${ }^{41}$ and embedded tools in the notes to provide lay definitions of medical terminology for patients ${ }^{42}$ are being developed. 


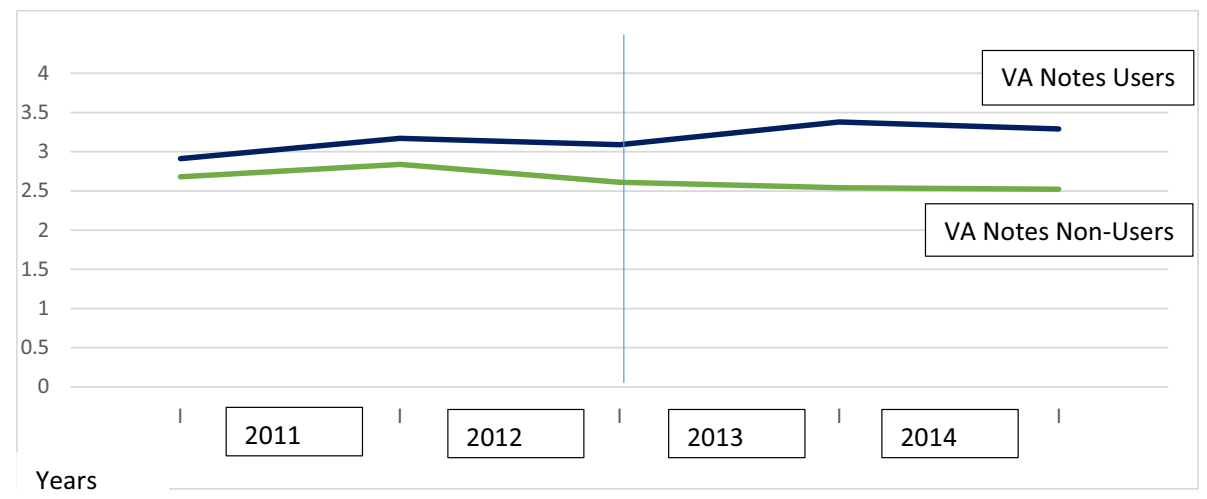

\begin{tabular}{|c|c|c|c|c|c|}
\hline & 2010 & 2011 & 2012 & 2013 & 2014 \\
\hline \multicolumn{6}{|c|}{ Number of Primary Care Appointments - VA Notes Users } \\
\hline Median & 3 & 3 & 3 & 4 & 4 \\
\hline Mean (SD) & $2.907(1.805)$ & $3.173(1.659)$ & $3.090(1.693)$ & $3.377(1.717)$ & $3.288(1.846)$ \\
\hline \multicolumn{6}{|c|}{ Number of Primary Care Appointments - Non-Users of VA Notes } \\
\hline Median & 3 & 3 & 2 & 2 & 2 \\
\hline Mean (SD) & $2.681(1.803)$ & $2.847(1.721)$ & $2.608(1.773)$ & $2.537(1.851)$ & $2.523(1.935)$ \\
\hline \multicolumn{6}{|c|}{ Difference in Mean Number of Primary Care Appointments } \\
\hline $\begin{array}{l}\text { ON Users } \\
\text { versus non- } \\
\text { ON users }\end{array}$ & 0.226 & 0.326 & 0.482 & 0.84 & 0.765 \\
\hline
\end{tabular}

Figure 2 Average number of primary care appointments: VA Notes users versus non-users pre- and post-VA Notes implementation. VA Notes users are patients who accessed clinical notes in their electronic health record, including notes from physicians, nurses, and other healthcare personnel, following the VA Notes implementation.

\section{Limitations}

There are several limitations of this study. Like all nonexperimental studies, these associations are observational and, thus, causality cannot be directly known. For example, there may be an effect of clinic use on viewing notes, since it is possible that patients were referred to view their portal during a clinic visit. A longitudinal analysis examining the timing of note access and scheduling of clinical visits would further enhance understanding. Note that this analysis is retrospective, and only represents the immediate impact of open notes over the first 4 years of implementation. Thus, our findings do not reflect the longer term impact of notes. We can only speculate, based on the fact that the change in visits was small and relatively flat after 2 years, that it is possible that these trends have continued. Certainly, the total number of Veterans using My Health$\boldsymbol{e V}$ et has continued to increase, and likely the overall use of notes as well.

Table 2 Clinical Note Documentation, Pre- and Post-VA Notes Implementation

\begin{tabular}{|c|c|c|c|c|c|c|c|c|c|c|c|c|}
\hline & \multirow{2}{*}{\multicolumn{4}{|c|}{ Entire clinical note }} & \multicolumn{8}{|c|}{ Clinical note } \\
\hline & & & & & \multicolumn{4}{|c|}{ Assessment and plan } & \multicolumn{4}{|c|}{ History of present illness } \\
\hline & $\begin{array}{l}\text { Pre } \\
\text { Mean } \\
\text { (SD) }\end{array}$ & $\begin{array}{l}\text { Post } \\
\text { Mean } \\
\text { (SD) }\end{array}$ & $\begin{array}{l}\text { Mean } \\
\text { Diff } \\
\text { (SD) }\end{array}$ & $\begin{array}{l}p \\
\text { value }\end{array}$ & $\begin{array}{l}\text { Pre } \\
\text { Mean } \\
\text { (SD) }\end{array}$ & $\begin{array}{l}\text { Post } \\
\text { Mean } \\
\text { (SD) }\end{array}$ & $\begin{array}{l}\text { Mean } \\
\text { Diff } \\
\text { (SD) }\end{array}$ & $\begin{array}{l}p \\
\text { value }\end{array}$ & $\begin{array}{l}\text { Pre } \\
\text { Mean } \\
\text { (SD) }\end{array}$ & $\begin{array}{l}\text { Post } \\
\text { Mean } \\
\text { (SD) }\end{array}$ & $\begin{array}{l}\text { Mean } \\
\text { Diff } \\
\text { (SD) }\end{array}$ & $\begin{array}{l}p \\
\text { value }\end{array}$ \\
\hline Word count & $\begin{array}{l}885.7 \\
(458.1)\end{array}$ & $\begin{array}{l}923.6 \\
(457.5)\end{array}$ & $\begin{array}{l}37.9 \\
(180.8)\end{array}$ & 0.19 & $\begin{array}{l}109.9 \\
(86.7)\end{array}$ & $\begin{array}{l}116.5 \\
(99.1)\end{array}$ & $\begin{array}{l}6.7 \\
(44.2)\end{array}$ & 0.35 & $\begin{array}{l}97.2 \\
(65.8)\end{array}$ & $\begin{array}{l}103.5 \\
(69.8)\end{array}$ & $\begin{array}{l}6.3 \\
(34.9)\end{array}$ & 0.26 \\
\hline $\begin{array}{l}\text { Words per } \\
\text { sentence }\end{array}$ & $\begin{array}{l}5.6 \\
(0.7)\end{array}$ & $\begin{array}{l}6.7 \\
(1.5)\end{array}$ & $\begin{array}{l}1.0 \\
(1.5)\end{array}$ & $<$ & $\begin{array}{l}11.2 \\
(6.4)\end{array}$ & $\begin{array}{l}11.5 \\
(8.7)\end{array}$ & $\begin{array}{l}0.3 \\
(6.4)\end{array}$ & 0.78 & $\begin{array}{l}14.9 \\
(9.1)\end{array}$ & $\begin{array}{l}12.9 \\
(8.2)\end{array}$ & $\begin{array}{l}-2.0 \\
(6.9)\end{array}$ & 0.08 \\
\hline Reading ease & $\begin{array}{l}53.8 \\
(10.1)\end{array}$ & $\begin{array}{l}50.8 \\
(9.9)\end{array}$ & $\begin{array}{l}-3.1 \\
(9.0)\end{array}$ & $.04 *$ & $\begin{array}{l}37.5 \\
(19.0)\end{array}$ & $\begin{array}{l}35.5 \\
(20.7)\end{array}$ & $\begin{array}{l}-2.0 \\
(12.4)\end{array}$ & 0.32 & $\begin{array}{l}45.0 \\
(22.2)\end{array}$ & $\begin{array}{l}46.6 \\
(24.4)\end{array}$ & $\begin{array}{l}1.6 \\
(21.1)\end{array}$ & 0.64 \\
\hline Grade level & $\begin{array}{l}7.1 \\
(1.4)\end{array}$ & $\begin{array}{l}7.7 \\
(1.7)\end{array}$ & $\begin{array}{l}0.7 \\
(1.3)\end{array}$ & $<0.01 *$ & $\begin{array}{l}8.6 \\
(3.7)\end{array}$ & $\begin{array}{l}8.8 \\
(4.1)\end{array}$ & $\begin{array}{l}0.2 \\
(3.1)\end{array}$ & 0.69 & $\begin{array}{l}8.8 \\
(4.1)\end{array}$ & $\begin{array}{l}7.5 \\
(4.0)\end{array}$ & $\begin{array}{l}-1.3 \\
(4.0)\end{array}$ & $0.05^{*}$ \\
\hline $\begin{array}{l}\text { Frequency of } \\
\text { abbreviations }\end{array}$ & $\begin{array}{l}26.4 \\
(18.2)\end{array}$ & $\begin{array}{l}24.9 \\
(15.7)\end{array}$ & $\begin{array}{l}-1.6 \\
(8.5)\end{array}$ & 0.26 & $\begin{array}{l}5.3 \\
(5.1)\end{array}$ & $\begin{array}{l}5.1 \\
(5.2)\end{array}$ & $\begin{array}{l}-0.2 \\
(2.3)\end{array}$ & 0.65 & $\begin{array}{l}3.0 \\
(2.8)\end{array}$ & $\begin{array}{l}2.9 \\
(2.8)\end{array}$ & $\begin{array}{l}-0.1 \\
(1.8)\end{array}$ & 0.82 \\
\hline $\begin{array}{l}\text { Number of } \\
\text { abbreviations }\end{array}$ & $\begin{array}{l}14.3 \\
(7.9)\end{array}$ & $\begin{array}{l}13.5 \\
(6.8)\end{array}$ & $\begin{array}{l}-0.8 \\
(3.6)\end{array}$ & 0.17 & $\begin{array}{l}4.2 \\
(3.6)\end{array}$ & $\begin{array}{l}4.2 \\
(3.8)\end{array}$ & $\begin{array}{l}-0.1 \\
(1.5)\end{array}$ & 0.69 & $\begin{array}{l}2.6 \\
(1.9)\end{array}$ & $\begin{array}{l}2.6 \\
(2.3)\end{array}$ & $\begin{array}{l}-0.01 \\
(1.4)\end{array}$ & 0.96 \\
\hline
\end{tabular}

*100 patients were randomly selected from 40 primary care providers who had the highest percentage of portal users on their panel. We examined their clinical note documentation pre- and post-VA Notes implementation 


\section{Future Implications}

Access to clinical notes is a Federal mandate for all patients as of November $2020 .{ }^{43}$ Our results on the impact of the national rollout of VA Notes may provide insight for other healthcare organizations considering the potential impact of OpenNotes on their organization, as unintended consequences associated with new innovations are often seen early post-implementation. In the VA, viewing notes coincided with a short-term trend of increased clinical visits; however, VA Notes did not substantially change clinician's note-writing behavior as assessed by reading ease. Additional tools and resources may also assist patients in understanding their notes for enhanced self-management. ${ }^{44}$

Corresponding Author: Amanda C. Blok, Veterans Affairs Center for Clinical Management Research, Veterans Affairs Ann Arbor Healthcare System, United States Department of Veterans Affairs, 2215 Fuller Road, Mail Stop 152, Ann Arbor, MI, USA (e-mail: Amanda.Blok@va.gov).

Funding This study was funded by the Department of Veteran Affairs (grant VA241-12-D-0224).

\section{Compliance with Ethical Standards:}

This study was reviewed and approved by the Edith Nourse Rogers Memorial Veterans Hospital and the University of Massachusetts Medical School Institutional Review Boards.

Conflict of Interest: The authors declare that they do not have a conflict of interest.

\section{REFERENCES}

1. Bodenheimer T, Chen E, Bennett HD. Confronting the growing burden of chronic disease: can the US health care workforce do the job? Health Affairs. 2009; 28(1): 64-74.

2. Coleman $\mathbf{K}$, et al. Evidence on the chronic care model in the new millennium. Health Affairs. 2009; 28(1): 75-85.

3. Center for Medicaid and Medicare Services. Medicare and Medicaid programs; electronic health record incentive program. Final rule. Federal register, 2010. 75(144): 44313.

4. Vydra TP, et al. Diffusion and Use of Tethered Personal Health Records in Primary Care. Perspect Health Inf Manag. 2015; 12: 1c.

5. Department of Health and Human Services. 2016 Report to Congress on Health IT Progress: Examining the HITECH Era and the Future of Health IT. 2016.

6. Nazi KM, et al. Consumer health informatics: engaging and empowering patients and families, in Clinical Informatics Study Guide. 2016; Springer. p. 459-500.

7. Xerox Healthcare Services, S.O, Annual Xerox EHR Survey: Americans Open to Viewing Test Results, Handling Healthcare Online. 2014

8. Families NPFWA. New Survey: Patients Increasingly Value Electronic Health Records; Eager for More Access and Features. 2014.

9. Nazi KM, et al. Evaluating patient access to Electronic Health Records: results from a survey of veterans. Med Care. 2013; 51(3 Suppl 1): p. S52-6.

10. Woods SS, et al. Patient experiences with full electronic access to health records and clinical notes through the My HealtheVet Personal Health Record Pilot: qualitative study. J Med Internet Res. 2013; 15(3): e65.

11. Leveille SG, et al. Evaluating the impact of patients' online access to doctors' visit notes: designing and executing the OpenNotes project. BMC medical informatics and decision making. 2012; 12(1): p. 1.

12. Delbanco T, et al., Open notes: doctors and patients signing on. Ann Intern Med. 2010; 153(2): 121-5.
13. Delbanco T, et al. Inviting patients to read their doctors' notes: a quasiexperimental study and a look ahead. Ann Intern Med. 2012; 157(7): 461-70.

14. OpenNotes. Our history: Fifty years in the making. 2019; Available from: https://www.opennotes.org/history/. 17 Aug. 2020.

15. Nazi KM, et al. VA OpenNotes: exploring the experiences of early patient adopters with access to clinical notes. Journal of the American Medical Informatics Association. 2014: amiajnl-2014-003144.

16. My HealtheVet. Learn more about My HealtheVet notes. 2019; Available from: https://www.myhealth.va.gov/mhv-portal-web/my-healthevet-vanotes-learn-more. 17 Aug. 2020.

17. Olenick M., Flowers M, Diaz VJ. US veterans and their unique issues: enhancing health care professional awareness. Adv Med Educ Pract. 2015; 6: 635-9.

18. Kazis LE, et al. Measurement comparisons of the medical outcomes study and veterans SF-36 health survey. Health Care Financ Rev. 2004; 25(4): 43-58

19. Yu W, et al. Prevalence and costs of chronic conditions in the VA health care system. Med Care Res Rev. 2003; 60(3 Suppl): 146S-167S.

20. Lee TA, et al. Mortality rate in veterans with multiple chronic conditions. J Gen Intern Med. 2007; 22 Suppl 3: 403-7.

21. Cohen BE, et al. Association of cardiovascular risk factors with mental health diagnoses in Iraq and Afghanistan war veterans using VA health care. JAMA; 2009. 302(5): 489-92.

22. Nazi KM, et al. VA OpenNotes: exploring the experiences of early patient adopters with access to clinical notes. J Am Med Inform Assoc. 2015; 22(2): 380-9.

23. Veterans Health Administration. 2020 August 10, 2020]; Available from: https://www.va.gov/health/. 17 Aug. 2020.

24. Ancker, J.S., B. Hafeez, and R. Kaushal, Socioeconomic disparities in adoption of personal health records over time. The American journal of managed care, 2016. 22(8): p. 539.

25. Mafi JN, et al. Patients learning to read their doctors' notes: the importance of reminders. Journal of the American Medical Informatics Association, 2016: ocv167.

26. Gerard M, et al. The Importance of Visit Notes on Patient Portals for Engaging Less Educated or Nonwhite Patients: Survey Study. J Med Internet Res. 2018. 20(5): e191.

27. Walker $\mathbf{J}$, et al. OpenNotes After 7 Years: Patient Experiences With Ongoing Access to Their Clinicians' Outpatient Visit Notes. J Med Internet Res. 2019; 21(5): e13876.

28. Ammenwerth E, Schnell-Inderst P, Hoerbst A. The impact of electronic patient portals on patient care: a systematic review of controlled trials. J Med Internet Res. 2012; 14(6): p. el62.

29. Ross SE, et al. Providing a web-based online medical record with electronic communication capabilities to patients with congestive heart failure: randomized trial. J Med Internet Res. 2004; 6(2): e12.

30. Palen, T.E., et al., Association of online patient access to clinicians and medical records with use of clinical services. JAMA. 2012; 308(19): 2012-9

31. Choudhry AJ, et al. Readability of discharge summaries: with what level of information are we dismissing our patients? Am J Surg. 2016; 211(3): 631-6.

32. Flesch R. A new readability yardstick. J Appl Psychol. 1948; 32(3): 221-33.

33. Edmunds MR, Barry RJ, Denniston AK. Readability assessment of online ophthalmic patient information. JAMA Ophthalmol. 2013; 131(12): 1610-6.

34. Ancker JS, et al. Use of an electronic patient portal among disadvantaged populations. J Gen Intern Med. 2011; 26(10): 1117-23.

35. Shimada SL, et al. Personal health record reach in the Veterans Health Administration: a cross-sectional analysis. Journal of medical Internet research. 2014; 16(12): e272.

36. Kontos E, et al. Predictors of eHealth usage: insights on the digital divide from the Health Information National Trends Survey 2012. J Med Internet Res, 2014. 16(7): e172.

37. Zickuhr K, Madden M. Older Adults and Internet Use. 2012 [cited 2017 March 10, 2017]; Available from: http://www.pewinternet.org/2012/06/ 06/older-adults-and-internet-use/. 17 Aug. 2020.

38. Esch T, et al. Engaging patients through open notes: an evaluation using mixed methods. BMJ Open. 2016; 6(1): e010034.

39. Jackson SL, et al. Patients who share transparent visit notes with others: characteristics, risks, and benefits. J Med Internet Res. 2014; 16(11): e247.

40. Safeer RS, Keenan J. Health literacy: the gap between physicians and patients. Am Fam Physician. 2005; 72(3): 463-8. 
41. Dobscha SK, et al. Impacts of a Web-Based Course on Mental Health Clinicians' Attitudes and Communication Behaviors Related to Use of OpenNotes. Psychiatr Serv. 2019; 70(6): 474-479.

42. Chen $\mathbf{J}$, et al. A natural language processing system that links medical terms in electronic health record notes to lay definitions: system development using physician reviews. Journal of medical Internet research. 2018; 20(1): e26.

43. Federal Resgister. 21st Century Cures Act: Interoperability, information blocking and the ONC Health IT certification Program. 2020; Available from: https://www.federalregister.gov/documents/2020/05/01/2020- 07419/21st-century-cures-act-interoperability-information-blockingand-the-onc-health-it-certification. 17 Aug. 2020.

44. Polepalli Ramesh B, et al. Improving patients' electronic health record comprehension with NoteAid. Stud Health Technol Inform. 2013; 192: 714-8.

Publisher's Note: Springer Nature remains neutral with regard to jurisdictional claims in published maps and institutional affiliations. 